\title{
Opinion \\ Some thoughts (and some defenses) on modern psychiatric practice
}

\begin{abstract}
This brief opinion article presents 10 critiques regarding modern training and practice of clinical psychiatry in the United States from the perspective of a psychologist who works closely with psychiatric prescribers. Issues covered include polypharmacy and use of psychotropic medication, conceptual and theoretical orientations of psychopathology, and diagnostics/nosology.
\end{abstract}

Keywords: Psychiatry; Psychology
Volume I Issue 5 - 2014

\section{Eric S Rogers}

Robley Rex Veterans Affairs Medical Center, USA

Correspondence: Eric S Rogers, Robley Rex Veterans Affairs Medical Center, 800 Zorn Ave Louisville, KY, USA, Tel 502-6240224,Email eric.rogers2@va.gov

Received: October 0I, 20I4 | Published: October 14, 2014

\section{Opinion}

I recently had a student of mine ask for my personal critique of psychiatry/current psychiatric training. As a practicing clinical psychologist who works closely with our sister profession on a daily basis, I was happy to oblige. Because the question was submitted to me via email, I began drafting a written response. However, before I knew it, my email had turned into a significant writing piece. Not wanting my musing on the topic to be limited to just this one student, I thought I might tweak my hastily written email into a document that my professional peers could view and weigh-in on. I do not suppose this article will win me any popularity contests, but I do not find it to be unduly harsh or personal, and I could make a list twice as long about my own profession/field, trust me. The following is merely opinion of course, but I would like to think it is somewhat of an educated one.

I will begin with something that might seem quite shocking, perhaps even blasphemous to my clinical psychologist brethren. But, I think I will say it anyway. There is actually something that I do NOT think is terribly wrong with psychiatry. Ready? Polypharmacy. The debate about the overuse of psychotropicscan, I think, superficially appears to be a bunch of thoughtless psychiatrists who are over liberal in their practice because of a lack of concern over risks. Yet, despite the emphasis on evidence based practice, polypharmacy with mixtures of similar classes of medications is common place, at least in my experience. I would postulate that this is more because psychiatry is complex, and our patients struggle to get better as opposed to carelessness, or worse yet, a lack of caring.

Moreover, as unappealing as it may be to our tastes, or even our view of mental hygiene, if a medication has been shown to provide relief (even mild relief) from psychic suffering, I believe psychiatric practitioners are ethically (and morally) obligated to present this as a treatment option. There is such thing as over steering, and adding a new medicine with each new complaint and this is clearly bad practice, but how many visits do we need to see a patient who is suffering before we decide to be less conventional? IS it the "art" of psychopharmacology? I am a reluctant supporter and advocate, I must say. Although, I submit that while I loathe the development of the "15-minute med check" model of care, I also realize that we currently have a limited arsenal of weapons in the fight against psychic distress. And while I agree that "pills don't teach skills," I think all of us, psychologists especially, could use a little bit of humbling when it comes to how effective we are as treaters of the human psyche. Spending much of my day doing brief, evidence-based therapies within a primary care clinic, I can tell you my success rate is far from what I would like it to be. Medication or therapy, both is often times futile in our 50 minute attempts to counteract the social, environmental, and life forces that brought them to our office in the first place. My advisor/mentor in graduate school once told me that single most potent determinant of mental disorder is often overlooked even by the most educated of professionals: bad luck. I have yet to figure out how to treat that one.

Here are the real issues, in my opinion

1. Psychiatry has become too focused on the DSM, with a complete de-emphasis of descriptive psychopathology a la Kraepelin, Bleuler, Jaspers, Schneider etc.

2. In my experience, surprisingly little attention is paid to medical differential diagnosis of psychiatric presentations (autoimmune, infectious, metabolic, vascular etc.) in the outpatient setting. ER/ ED and inpatient attending seem to address this well, however.

3. There is not enough attention paid to the toxic effects of psychiatric drugs and iatrogenic syndromes such as super sensitivity psychosis, tardive dysphoria syndrome, tardive dysmentia, antidepressant-induced chronic irritable dysphoria that are caused by long-term use of psychiatric drugs.

4. In talking with my psychiatric colleagues, I am surprised how little training they get in sensible ways of actually withdrawing people off of psychotropic drug regimens, rather than simply tapering one and titrating another in its place.

5. In my experience, psychiatrists don't take care of the syndromes (or at least not very well) that they cause in their patients. Such as diabetes/metabolic syndrome, hypertension, etc.

6. There is too much emphasis on psychodynamic theories of mind whilst many (but not all) psychiatrists remain oblivious to other less ridiculous psychological theories that actually provide a useful framework for understanding problems and treating patients in a timely fashion. While clinical psychology moves ahead in this realm, psychiatry consistently falls further and further behind.

7. Psychiatry has completely eschewed the social basis of psychopathology. Most of our patients are at the mercy of wider social forces and psychiatric services are, frankly, the last thing they need, and certainly the least important part of their 
recovery. Yet, in adult psychiatry, the role of social factors in psychopathology is completely underplayed, and some things seem to be ignored completely (e.g., relationship between race and psychopathology).

8. Psychiatry is almost wholly a "reactive" practice. A fundamental element of my training as a clinical psychologist was the "dissemination" of psychological science for the purposes of promoting healthy behaviors and attenuating unhealthy behaviors BEFORE they result in a crisis or undue harm. There is so much more that the psychiatric profession could do to promote mental hygiene.

9. Psychiatry has become too disconnected from its scientific cousin, psychology. I am often aghast at how little psychology some psychiatrists seem to know, from cognitive biases that affect their clinical judgments/conclusions, to the basic schedules of learning and reinforcement (what do you mean you don't know your ABCs?), to social psychological factors that influences their patients' decisions and behavior.

10. I view my mild defense of polypharmacy as acceptable/justifiable because I largely view it as a symptom of something deeper and more fundamentally problematic. That is, the medicalization of psychological distress. A fundamental principle of most psychotherapy treatments, cognitive-behavioral therapy in particular, is that personal agency is a necessary component in the mastering of emotional distress. When one ascribes symptom reduction to a pill rather than their own sense of mastery, I often wonder if we have done them a favor, or simply enrolled them in recurring club membership of which they did not provide full informed consent to join.

\section{Acknowledgments}

None.

\section{Conflicts of interest}

Author declares there are no conflicts of interest.

\section{Funding}

None. 